\title{
Variability of Postnatal Ossification Timing and Evidence for a "Dosage" Effect
}

\author{
STANLEY M. GARN AND LAWRENCE D. MCCREERY \\ Center for Human Growth and Development, University of Michigan, \\ Ann Arbor, Michigan
}

\begin{abstract}
Although absolute variability in postnatal ossification timing is generally larger in boys than in girls, relative, conception-corrected variability is significantly larger in girls, suggestive of a "dosage" effect and consistent with the hypothesis of partial X-linkage. These findings, together with the excess of sister-sister over brother-brother timing similarities are inconsistent with the hypothesis of selective inactivation of either the paternal or the maternal $X$ chromosome.
\end{abstract}

In previous studies on postnatal ossification timing, we have explored various aspects of genetic control, as studied both within generation and between them. The reports have emphasized the familial nature of "atypical" ossification sequences and sequence polymorphisms (Garn and Rohmann, '60, '62b; Garn, Rohmann and Davis, '63; Garn, Rohmann and Blumenthal, '66; Garn, Rohmann and Silverman, '67) and the evidence for both autosomal and sex-linked inheritance (Garn and Rohmann, '62a, '69). Both the studies of sequence variability and sequence polymorphism and the investigations on the mechanisms of control have indicated the need for a comprehensive analysis of variability in ossification timing, center by center, in part to test for a "dosage effect," and in part to relate sequence variability to ossification timing variability per se.

The present paper, therefore, is concerned with three aspects of variability in postnatal ossification timing. It is first concerned with the sex difference in absolute variability of 73 postnatal centers, with particular reference to the late appearing "adolescent" centers. Second, it is concerned with the sex difference in relative or age-corrected variability, with specific reference to possibly enhanced relative variability in the female, consistent with the hypothesis of partial mediation of the $\mathrm{X}$ chromosome. Third, it is concerned with the implications of ossification timing variability to sequence variability and sequence polymorphisms, to missing secondary centers of ossification and to the com- munality of ossification timing and the predictive efficiency of different centers of ossification.

\section{MATERIALS AND METHODS}

This study is based upon cumulative ageat-appearance data on 73 postnatal ossification centers of the hand, foot, elbow, knee, shoulder and hip, and including epiphyses, round bones and primary centers. The fifteenth and eighty-fifth percentiles were recalculated from the data earlier employed by us (Garn, Rohmann and Silverman, '67), and were then used to estimate ossification timing variability (i.e. $\delta^{2}$ ) center by center, and for boys and girls respectively.

For each center, and for boys and girls separately, relative variance was also calculated as the familiar coefficient of variation (C. V.) thus relating absolute variability in postnatal ossification timing to the conception-corrected median age at appearance, for the center and sex in question. The familiar $F$ test was employed to determine the significance of sex differences in ossification timing variance, and the $t$ test was employed to compare pooled data on both absolute and relative variance. With 73 postnatal centers, the stochastic chi-squared test could also be applied without the need for Yates' correction for continuity.

The primary question was whether and to what extent relative variability in postnatal ossification timing was greater in the female than in the male, consistent with the hypothesis of partial X-linkage, and 
therefore a greater range of expression in the XX. However, as arranged in tabular form, the presentation also called attention to centers of unusual variability, and a tendency for reduction in both absolute and relative variability in the late appearing centers.

These ossification data relate to wellnourished subjects primarily of Northwest European ancestry. In other populations, delayed ossification timing or age-increased variability might yield different values, particularly for those centers where sequence polymorphisms are more or less common. Further, the effects of caloric malnutrition, protein-calorie malnutrition or the combination of malnutrition and infection would be to delay ossification timing and to increase absolute and relative ossification variability differentially (cf. Garn and Rohmann, '66).

\section{Findings}

As shown in the first table, where data on ossification timing variability of individual centers are set forth, boys expectably exceed girls in timing variability of the majority of centers. This is true for 60 out of 73 postnatal ossification centers, and the resulting value of chi-squared is then highly significant against the chance (36.5: 36.5) hypothesis. For most of these 73 centers variance is also significantly greater for the boys by the $F$ test. The exceptions are primarily the late-appearing centers that follow the distal epiphysis of the ulna, and include as a group the "adolescent centers" - the adductor sesamoid of the thumb to the ischial tuberosity, inclusive (see table 1 ).

However, when variability of postnatal ossification timing is expressed in relation to the conception-corrected age at appearance, as the coefficient of variation, the sex rankings of variability then tend to reverse. Relative ossification timing variability proves to be greater for girls in 51 out of 73 postnatal ossification centers, and the resulting stochastic chi-squared value is then 11.52. So relative age-corrected variability of postnatal ossification timing is somewhat greater for girls, when comparison is made on a center-by-center basis, as shown in detail in the table.

Examing those centers having a conception-corrected coefficient of variation in excess of 19.5 , with a view toward a functional explanation, no general relationship emerges; the centers high in relative ossification variability are not unusual in ossification timing communality (mean $r$ ) nor in relative (per cent) sexual dimorphism. This is confirmed by low correlation coefficients between the coefficients of variation and the predictive rankings as given in Garn, Rohmann and Silverman, '67,

TABLE 1

Absolute and relative variability in postnatal ossification of boys and girls

\begin{tabular}{|c|c|c|c|c|c|}
\hline \multirow{2}{*}{ Center of ossification } & \multicolumn{2}{|c|}{$\begin{array}{l}\text { Standard } \\
\text { deviation }\end{array}$} & \multirow{2}{*}{$\begin{array}{l}\text { Signifi- } \\
\text { cance of } \\
F\end{array}$} & \multicolumn{2}{|c|}{$\begin{array}{l}\text { Coefficient } \\
\text { of } \\
\text { variation }\end{array}$} \\
\hline & Boys & Girls & & Boys & Girls \\
\hline Head, humerus & 0.14 & 0.13 & - & 0.19 & 0.17 \\
\hline Proximal epiphysis, tibia & 0.03 & 0.02 & 0.01 & 0.04 & 0.02 \\
\hline Coracoid process, scapula & 0.16 & $0.19 *$ & 0.05 & 0.20 & 0.25 \\
\hline Cuboid, tarsus & 0.11 & 0.05 & 0.01 & 0.14 & 0.07 \\
\hline Capitate, carpus & 0.17 & $0.20 *$ & - & 0.17 & 0.23 \\
\hline Hamate, carpus & 0.20 & $0.20 *$ & - & 0.19 & 0.22 \\
\hline Capitulum, humerus & 0.25 & 0.18 & 0.01 & 0.23 & 0.18 \\
\hline Head, femur & 0.14 & 0.14 & - & 0.13 & 0.13 \\
\hline Lateral ( 3 rd) cuneiform, tarsus & 0.38 & $0.50 *$ & 0.05 & 0.32 & 0.51 \\
\hline Greater tubercle, humerus & 0.52 & 0.23 & 0.01 & 0.33 & 0.19 \\
\hline Primary center, middle phalanx 5 th toe & 1.38 & 0.67 & 0.01 & 0.77 & 0.45 \\
\hline Distal epiphysis, radius & 0.44 & 0.33 & 0.01 & 0.24 & 0.21 \\
\hline Epiphysis, distal phalanx 1st toe & 0.35 & 0.32 & - & 0,18 & 0.21 \\
\hline Epiphysis, middle phalan $x$ th toe & 0.62 & 0.65 * & - & 0.32 & 0.39 \\
\hline Epiphysis, proximal phalanx 3 rd finger & 0.35 & 0.30 & - & 0.16 & 0.19 \\
\hline Epiphysis, middle phalanx 3rd toe & 0.96 & 0.56 & 0.01 & 0.45 & 0.32 \\
\hline
\end{tabular}


TABLE 1 (Continued)

Absolute and relative variability in postnatal ossification of boys and girls

\begin{tabular}{|c|c|c|c|c|c|}
\hline \multirow[t]{2}{*}{ Center of ossification } & \multicolumn{2}{|c|}{$\begin{array}{l}\text { Standard } \\
\text { deviation }\end{array}$} & \multirow{2}{*}{$\begin{array}{l}\text { Signifi- } \\
\text { cance of } \\
F\end{array}$} & \multicolumn{2}{|c|}{$\begin{array}{c}\begin{array}{c}\text { Coefficient } \\
\text { of } \\
\text { variation }\end{array} \\
\end{array}$} \\
\hline & Boys & Girls & & Boys & Girls \\
\hline Epiphysis, proximal phalanx 2nd finger & 0.35 & 0.31 & - & 0.16 & 0.19 \\
\hline Epiphysis, proximal phalanx 4 th finger & 0.40 & 0.31 & 0.05 & 0.18 & 0.19 \\
\hline Epiphysis, distal phalanx 1st finger & 0.49 & 0.33 & 0.01 & 0.22 & 0.22 \\
\hline Epiphysis, proximal phalanx 3rd toe & 0.40 & 0.34 & $\longrightarrow$ & 0.17 & 0.19 \\
\hline Epiphysis, 2nd metacarpal & 0.47 & 0.26 & 0.01 & 0.20 & 0.14 \\
\hline Epiphysis, proximal phalanx 4 th toe & 0.42 & 0.36 & - & 0.18 & 0.18 \\
\hline Epiphysis, proximal phalanx 2nd toe & 0.42 & 0.36 & - & 0.17 & 0.18 \\
\hline Epiphysis, 3rd metacarpal & 0.51 & 0.32 & 0.01 & 0.20 & 0.17 \\
\hline Epiphysis, proximal phalanx 5th finger & 0.45 & 0.36 & 0.05 & 0.17 & 0.18 \\
\hline Epiphysis, middle phalanx 3rd finger & 0.58 & 0.43 & 0.01 & 0.21 & 0.21 \\
\hline Epiphysis, 4th metacarpal & 0.63 & 0.35 & 0.01 & 0.23 & 0.17 \\
\hline Epiphysis, middle phalanx 2nd toe & 0.79 & 0.44 & 0.01 & 0.28 & 0.23 \\
\hline Epiphysis, middle phalanx 4 th finger & 0.56 & 0.45 & 0.05 & 0.20 & 0.23 \\
\hline Epiphysis, 5th metacarpal & 0.64 & 0.37 & 0.01 & 0.22 & 0.18 \\
\hline Medial (1st) cuneiform, tarsus & 0.72 & 0.58 & 0.05 & 0.25 & 0.27 \\
\hline Epiphysis, 1st metatarsal & 0.43 & 0.32 & 0.01 & 0.15 & 0.14 \\
\hline Epiphysis, middle phalanx and finger & 0.50 & 0.47 & - & 0.17 & 0.22 \\
\hline Epiphysis, proximal phalanx 1st toe & 0.46 & 0.39 & 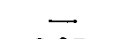 & 0.15 & 0.17 \\
\hline Epiphysis, distal phalanx 3rd finger & 0.60 & 0.49 & 0.05 & 0.19 & 0.22 \\
\hline Triquetral, carpus & 1.24 & 0.86 & 0.01 & 0.39 & 0.35 \\
\hline Epiphysis, distal phalanx 4th finger & 0.59 & 0.52 & $\longrightarrow$ & 0.18 & 0.23 \\
\hline Epiphysis, proximal phalanx 5th toe & 0.53 & 0.42 & 0.05 & 0.17 & 0.17 \\
\hline Epiphysis, 1st metacarpal & 0.72 & 0.44 & 0.01 & 0.21 & 0.19 \\
\hline Intermediate ( 2 nd) cuneiform, tarsus & 0.75 & 0.55 & 0.01 & 0.22 & 0.21 \\
\hline Epiphysis, 2nd metatarsal & 0.60 & 0.55 & - & 0.17 & 0.19 \\
\hline Greater trochanter, femur & 0.61 & 0.52 & 一 & 0.16 & 0.20 \\
\hline Ephiphysis, proximal phalanx 1st finger & 0.68 & 0.48 & 0.01 & 0.18 & 0.19 \\
\hline Navicular, tarsus & 1.07 & 0.70 & 0.01 & 0.28 & 0.26 \\
\hline Epiphysis, distal phalanx 2nd finger & 0.79 & 0.56 & 0.01 & 0.20 & 0.17 \\
\hline Epiphysis, distal phalanx 5th finger & 0.73 & 0.61 & - & 0.18 & 0.23 \\
\hline Epiphysis, middle phalanx 5th finger & 0.97 & 0.67 & 0.01 & 0.23 & 0.24 \\
\hline Proximal epiphysis, fibula & 0.85 & 0.65 & 0.05 & 0.20 & 0.19 \\
\hline Epiphysis, 3rd metatarsal & 0.67 & 0.57 & - & 0.16 & 0.17 \\
\hline Epiphysis, distal phalanx 5th toe & 0.99 & 0.73 & 0.01 & 0.21 & 0.24 \\
\hline Patella, knee & 0.85 & 0.63 & 0.01 & 0.18 & 0.20 \\
\hline Epiphysis, 4th metatarsal & 0.71 & 0.57 & 0.05 & 0.15 & 0.16 \\
\hline Lunate, carpus & 1.31 & 1.14 & - & 0.27 & 0.34 \\
\hline Epiphysis, distal phalanx 3rd toe & 0.80 & 0.68 & - & 0.16 & 0.20 \\
\hline Eriphysis, 5th metatarsal & 0.80 & 0.71 & - & 0.16 & 0.18 \\
\hline Epiphysis, distal phalanx 4 th toe & 0.86 & 0.68 & 0.05 & 0.17 & 0.20 \\
\hline Epiphysis, distal phalanx 2nd toe & 0.88 & 0.75 & - & 0.16 & 0.20 \\
\hline Head (capitulum), radius & 1.24 & 1.01 & 0.05 & 0.21 & 0.22 \\
\hline Scaphoid, carpus & 1.05 & 0.91 & - & 0.17 & 0.19 \\
\hline Trapezium, carpus & 1.36 & 1.10 & 0.05 & 0.21 & 0.23 \\
\hline Trapezoid, carpus & 1.34 & 0.91 & 0.01 & 0.19 & 0.18 \\
\hline Medial epicondyle, humerus & 1.03 & 0.76 & 0.01 & 0.15 & 0.18 \\
\hline Distal epiphysis, ulna & 0.95 & $1.08 *$ & - & 0.12 & 0.18 \\
\hline Eriphysis, calcaneus & 1.09 & 0.94 & - & 0.13 & 0.15 \\
\hline Olecranon, ulna & 1.03 & $1.08 *$ & - & 0.10 & 0.12 \\
\hline Lateral ericondyle, humerus & 1.12 & 1.03 & - & 0.09 & 0.10 \\
\hline Tubercle, tibia & 0.87 & $0.98 *$ & 一 & 0.07 & 0.09 \\
\hline Adductor sesamoid, 1st finger & 0.90 & $1.00 *$ & - & 0.07 & 0.09 \\
\hline Acetabulum, hip & 0.85 & $0.95 *$ & - & 0.06 & 0.08 \\
\hline Acromial extremity, clavicle & 0.83 & $0.87 *$ & - & 0.06 & 0.07 \\
\hline Epiphysis, iliac crest, hip & 0.97 & $1.12 *$ & - & 0.07 & 0.08 \\
\hline Accessory eniphysis, coracoid process, scapula & 0.89 & $1.00 *$ & - & 0.06 & 0.08 \\
\hline Ischial tuberosity, hip & 0.88 & $1.07 *$ & 0.05 & 0.05 & 0.07 \\
\hline
\end{tabular}

Arranged in order of increasing median age-at-appearance in boys, $F$ values significant at better than 0.01 shown as 0.01 , coefficients of variation calculated from conception-corrected median ages, stars designate centers where absolute values of sigma are greater in girls. 
table $5,(r=-0.12$ and -0.16$)$ and similarly low values of $r$ with per cent sexual dimorphism ( $r=0.12$ and 0.26 , respectively). However, there is a rather good correlation of 0.81 between relative ossifcation timing variability in boys and in girls, indicating that the relatively more variable centers are the same in both sexes.

Taken one at a time, the triquetral, lunate, trapezium, capitate and hamate are among the centers of higher relative ossification variability (C. V.) in both sexes, as are the lateral, medial and intermediate cuneiforms and the navicular (tarsus): the centers for these round bones are commonly involved in ossification sequence polymorphisms. Further, the epiphyses of the middle phalanxes of the second, third and fourth toes, and the distal phalanges of the fourth and fifth toes are among the secondary centers of increased relative ossification variability. These five centers frequently fail to develop as radiologically visible separate centers of ossification, in from 1 to 60 per cent of subjects.

Thus the findings attest to the greater absolute variability of postnatal ossification in boys, excluding the late appearing "adolescent" centers from this generalization. They also show the greater (relative) age-corrected variability of ossification timing in girls, including the last 12 postnatal centers as a group. They show the remarkable regularity of relative variability, such that those centers with higher coefficients of variability in boys are also higher in girls. Finally they identify certain centers of high variability in relative timing as centers also variable in other developmental respects, such as sequence polymorphisms and agenesis.

\section{DISCUSSION}

The findings in this study are both expected and unexpected. They are expected in that they confirm earlier evidence for greater ossification timing variability in boys (cf. Garn and Rohmann, '60 and discussions by Acheson, '66). They are unexpected in that the rather late ossification centers, particularly those that follow the adductor sesamoid of the thumb show greater absolute variability in girls. These late centers evidence both lesser ossifica- tion variability in boys, and diminished (per cent) sexual dimorphism in age-at-appearance (Garn, Rohmann and Silverman, '67, table 4). The onset of steroid mediation, therefore, neither increases variability nor increases sexual dimorphism in postnatal ossification timing.

The findings further reverse expectancy in showing that relative (age-corrected) ossification timing variability tends to be greater in girls throughout. While there is good agreement between center-specific coefficients of variation between boys and girls $(r=0.81)$, while the carpal and tarsal centers tend to be high in relative variability, and while the missing centers of the foot also evidence increased relative variability, neither ossification timing communality (mean $r$ ) nor per cent sexual dimorphism are particularly related to relative variability in ossification timing, as shown by the correlations. The increased relative variability in the of ten-missing foot centers (Garn, Rohmann and Silverman, '65) points to a relationship between agenesis and increased timing variability, such as we have previously described for the dentition (cf. Garn, Lewis and Bonne, '62).

Now the evidence for greater relative (age-corrected) ossification timing variability in girls is of itself consistent with the hypothesis of partial X-linkage. With two $X$ chromosomes rather than one, the female has a potentially wider range of genotypes, depending upon the mode of inheritance, the influence of autosomal genes, and the action of entire chromosomes rather than single genes. Given the evidence we have previously accumulated on siblings and parent-child pairs, all of which favor the assumption of an influence of the $X$ chromosome on ossification timing (Garn and Rohmann, '62a, '62b, '66) and as discussed by Hunt, ' 66 , Acheson, '66 and others, little more need be said about the additional evidence here. However, it is evident that the age-corrected variabilities in table 1 do not support the alternative hypothesis of either random or selective inactivation of the second $\mathrm{X}$ chromosome in the female. While increased fatherdaughter and sister-sister similarities could still occur if the maternal $X$ were selectively inhibited in girls, such selective in- 
hibition would be associated with decreased rather than increased relative timing variance in girls. ${ }^{1}$ Thus, at the present state of knowledge, postnatal ossification timing still appears to be mediated by autosomal genes plus those on the $\mathrm{X}$ chromosomes.

Now if two $X$ chromosomes make for greater variability in age-corrected ossification timing among the 73 centers here considered, how about two X chromosomes and a $Y$, or three X chromosomes or four, or five? This possibility we have considered and are now investigating, along with trisomy and translocations that may effect seqence, or order, but there are three operational limitations to the problem as posed. First there is the difficult problem of sampling, in order to establish estimates of ossification variability for the XXY, XXX, $\mathrm{XXYY}$, etc. Second, there is the problem of concomitant cardiovascular, neurological and enzymatic defects which limit growth and affect developmental variance. Third, there is the problem of the wholechromosome effect. Therefore, the simple assumption that ossification timing variability should be a linear function of the number of $\mathrm{X}$ chromosomes is less easily tested than stated.

But to return to the subject, it is increasingly clear that postnatal ossification timing is more than a series of standard values, and far more than a table of printed norms. True, the tabular data can be useful in the growth appraisal of individuals and of populations, in simple malnutrition and protein-calorie malnutrition as we have shown. Timing of appearance can also be used to document nutritional supplementation (Garn, Rohmann and Guzman, '66; Garn and Rohmann, '66). The relative timing in boys and girls follows surprisingly lawful and regular directions as expressed by a simple proximal-distal gradient of sexual dimorphism (Garn, '69). However, parent-child and sibling correlations and comparisons of variability in postnatal ossification timing also bear on the genetic control mechanisms. So far, fatherson, father-daughter, mother-son, motherdaughter, sister-sister, brother-brother, and sister-brother correlations for postnatal ossification timing as well as the data on relative variability presented here, all sug- gest some influence of the $\mathrm{X}$ chromosome. Taken together they are inconsistent with the hypothesis of either random or selective inactivation of the second $\mathrm{X}$ chromosome in the female, in contrast to some purely monogenic traits (cf. Gall, Moore and Brewer, '68).

Finally, the ossification behavior of the late-appearing adolescent centers deserves reiteration. These late centers are characterized by an unusually large excess of sister-sister over brother-brother similarities, generally greater absolute variability in girls as compared with boys, and consistently greater relative variability in girls. The excess of SS over $\mathrm{BB}$ is inconsistent with the hypothesis of selective inactivation of the paternal $X$ chromosome, the sigmas and C.V.s are inconsistent with the hypothesis of selective inactivation of the maternal $X$ chromosome in girls, and the per cent sex differences are inconsistent with the hypothesis of increased sexual dimorphism during the period of steroid mediation.

\section{ACKNOWLEDGMENTS}

This work was begun under grant No. AMO3816 and completed under grant AM13378 using facilities at the Center for Human Growth and Development under the direction of Mr. Richard L. Miller and the University of Michigan Computing Center. We appreciate the opportunity to review evidence for selective inactivation of an $\mathrm{X}$ chromosome in an unpublished manuscript of Dr. John C. Gall and we appreciate the assistance of Shirley M. Garrett in the manuscript preparation.

\section{LITERATURE CITED}

Acheson, R. M. 1966 Maturation of the skeleton. In: Human Development. F. Falkner, ed. W. B. Saunders, Philadelphia. pp 465-502.

Gall, J. C., G. W. Moore and G. J. Brewer 1968 Evidence for non-randomness of X-inactivation in heterozygous carriers of glucose-6-phosphate dehydrogenase (G6PD) deficiency. Clinical Research, 16: 452. (abstract)

Garn, S. M. 1969 The proximal-distal gradient of increasing sexual dimorphism in postnatal ossification timing. Am, J. Phys. Anthrop., in press.

1 While selective inactivation of an $\mathrm{X}$ chromosome has been demonstrated in some cell lines, this is not true for all and selective inactivation of the type suggested by Lyon probably does not occur at the tissue level. 
Garn, S. M., A. B. Lewis and B. Bonne 1961 Third molar polymorphism and the timing of tooth formation. Nature, 192: 989.

Garn, S. M., and C. G. Rohmann 1960 Variability in the order of ossification of the bony centers of the hand and wrist. Am. J. Phys. Anthrop., 18: 219-230.

- 1962a X-linked inheritance of develop. mental timing in man. Nature, 196: 695-696.

1962b Parent-child similarites in handwrist ossification. Am. J. Dis. Child., 103: 603-607.

1966 Interaction of nutrition and genetics in the timing and growth and development. Pediat. Clin. N. Amer., 13: 353-379.

Garn, S. M., C. G. Rohmann and T. Blumenthal 1966 Ossification sequence polymorphism and sexual dimorphism in skeletal development. Am. J. Phys. Anthrop., 24: 101-115.

Garn, S. M., C. G. Rohmann, and A. A. Davis 1963 Genetics of hand-wrist ossification. Am. J. Phys. Anthrop., 21: 33-40.
Garn, S. M., C. G. Rohmann and K. P. Hertzog 1969 Apparent influence of the $X$ chromosome on timing of 73 ossification centers. Am. J. Phys. Anthrop., 30: 123-128.

Garn, S. M., C. G. Rohmann and F. N. Silverman 1965 Missing secondary ossification centers of the foot. Inheritance and developmental timing. Ann. Radiol., 8: 629-644.

1967 Radiographic standards for postnatal ossification and tooth calcification. Med. Radiog. and Photog., 43: 45-66.

Garn, S. M., C. G. Rohmann and M. A. Guzman 1966 Malnutrition and skeletal development in the pre-school child. In: Pre-school Child Malnutrition: Primary Deterrant to Human Progress. National Academy of Sciences - National Research Council, pp 43-62.

Hunt, E, E. 1966 The developmental genetics of man. In: Human Development. F. Falkner, ed. W. B. Saunders, Philadelphia. pp 76-122. 